\title{
Trabalhadores e Segunda Guerra Mundial: debates introdutórios para um dossiê
}

\author{
Alexandre Fortes* \\ Felipe Ribeiro**
}

Diversas vertentes da história do trabalho no Brasil convergem na identificação da conjuntura situada entre 1941 e 1945 como um momento marcante tanto para a consolidação institucional do sistema varguista de relações de trabalho quanto para a emergência de um padrão de participação popular na política que viria a se constituir em base do projeto político trabalhista. Na maior parte da historiografia dedicada a esses temas, entretanto, a coincidência desses processos com o progressivo envolvimento do Brasil na Segunda Guerra Mundial costuma ser ignorada, ou, quando muito, tratada como um mero pano de fundo. Permanece imensamente influente, até os dias de hoje, por exemplo, a abordagem cunhada por Francisco Weffort, que enfatiza a reorganização do movimento operário no pós-guerra e afirma que a ditadura do Estado Novo havia apagado completamente a memória das lutas anteriores. ${ }^{1}$ Entretanto, já em 1981, o trabalho pioneiro de Alem ${ }^{2}$ demonstrou que as greves e as transformações vividas pelo sindicalismo no período de redemocratização tiveram origem no próprio contexto da guerra. Como comentaremos posteriormente, as conexões entre "esforço de guerra" e "pós-guerra" vêm sendo exploradas de forma pontual por diversos trabalhos nas últimas décadas. Até recentemente, porém, raros eram os autores que colocavam a conexão entre guerra e mundos do trabalho no centro de suas análises.

A proposta de organização deste dossiê partiu da avaliação de que esse cenário vem se alterando, e que hoje já é possível afirmar que a percepção das

Doutor em História pela Universidade Estadual de Campinas (Unicamp). Professor Associado da Universidade Federal Rural do Rio de Janeiro (UFRRJ). Bolsista de Produtividade do CNPq e Cientista do Nosso Estado FAPERJ. ORCID: https://orcid.org/0000-0002-3728-2318 . E-mail: fortes.ufrrj@gmail.com.

** Doutor em História, Política e Bens Culturais pela Fundação Getúlio Vargas (FGV). Professor Adjunto da Universidade Estadual do Piauí (UESPI). ORCID: http://orcid.org/0000-0002-12586550. E-mail: feliperibeiro@phb.uespi.br.

1 WEFFORT, Francisco. Origens do sindicalismo populista no Brasil (a conjuntura do após-guerra). Estudos Cebrap, n. 4, 1973. MARANHÃO, Ricardo. Sindicatos e Democratização (Brasil 1945/1950). São Paulo: Editora Brasiliense, 1979.

2 ALEM, Silvio Frank. Os Trabalhadores e a "Redemocratização": (estudo sobre o estado, partidos e a participação dos trabalhadores assalariados urbanos na conjuntura da guerra e do pós-guerra imediato) 1942-1948. Dissertação (Mestrado em História) - Universidade Estadual de Campinas, Campinas, 1981. 
múltiplas formas pelas quais a guerra se conecta à história do trabalho no período vem crescendo entre os historiadores brasileiros, gerando trabalhos de pesquisa extremamente originais, que dialogam com debates historiográficos internacionais de grande relevância. ${ }^{3}$

O papel das circunstâncias excepcionais criadas pela guerra total no fortalecimento da capacidade reguladora do Estado sobre a economia e nas formas de incorporação dos setores populares à cidadania está presente em uma grande diversidade de trabalhos historiográficos dedicados a períodos e países distintos. Hobsbawm atribui a própria sobrevivência da República Francesa, de 1792-1794, à invenção, pelos jacobinos, da moderna concepção de guerra total. Cercados pelos exércitos das maiores potências da Europa, os franceses saíram-se vencedores recorrendo à "total mobilização dos recursos de uma nação", obtida por meio "do recrutamento, do racionamento e de uma economia de guerra rigidamente controlada e da virtual abolição, em casa e no exterior, da distinção entre soldados e civis". A guerra desencadeou o protagonismo popular organizado em apoio ao governo revolucionário, cujos métodos "traziam a justiça social mais para perto", embora a militarização da política e da sociedade se demonstrasse incompatível "com a democracia direta, voluntária e descentralizada" que a sansculotterie almejava. ${ }^{4}$

Paradoxos semelhantes se tornaram recorrentes mesmo na trajetória histórica dos Estados Unidos, fartamente utilizado no discurso ideológico liberal como paradigma de sucesso das políticas de "estado mínimo".

Skocpol dedicou um trabalho clássico à análise de como a Guerra Civil norte-americana se constitui num exemplo da conexão entre guerra total, política sociais e cidadania. A autora analisou o programa pioneiro de gasto social generoso beneficiando os cidadãos idosos, deficientes e dependentes implementado durante a reconstrução. A política partidária competitiva do final do século XIX, resultante

3 As próximas páginas reproduzem, de forma sintética, argumentos já apresentados por um dos autores deste trabalho. FORTES, Alexandre. Os impactos da Segunda Guerra Mundial e a regulação das relações de trabalho no Brasil. Nuevo Mundo Mundos Nuevos, 27 jan. 2014. FORTES, Alexandre. World War II and brazilian workers: populism at the intersections between national and global histories. International Review of Social History, v. 62, Special Issue S25, p. 165-190, dec. 2017. FORTES, Alexandre. Do reformismo tecnocrático ao nacionalismo de massas: a Segunda Guerra Mundial e a emergência do trabalhismo brasileiro. FERRERAS, Norberto (ed.). A questão nacional e as tradições nacional-estatistas no Brasil, América Latina e África. Rio de Janeiro: Editora FGV, FAPERJ, 2015. p. 67-88.

4 HOBSBAWM, Eric. A era das revoluções: Europa 1789-1848. São Paulo: Paz e Terra, 1996. p. 85. 
da expansão do sufrágio, gerou a expansão dos benefícios para veteranos e suas famílias. Aexpectativa da implantação de uma política social universalista, entretanto, perdeu espaço na agenda política do país à medida que a geração que vivera a experiência da guerra ia desaparecendo, na virada do século. ${ }^{5}$

Em meados do século XX, nova experiência de guerra total tornou a abrir espaço para políticas intervencionistas no ambiente geralmente refratário dos EUA. John Kenneth Galbraith destaca que a resistência enfrentada pelas ideias keynesianas e a timidez das medidas anticíclicas no primeiro mandato de Franklin D. Roosevelt contribuíram para manter 9,5 milhões de americanos ( $17 \%$ da força de trabalho) desempregados ainda em 1939. O envolvimento norte-americano na guerra gerou a multiplicação dos gastos governamentais, e em 1942 vários setores sofriam de escassez de mão de obra. Com ironia, Galbraith comenta que Hitler "foi o verdadeiro protagonista das ideias keynesianas". ${ }^{6}$ Analisando o contexto de ação sindical do período, Nelson Lichtenstein destaca que embora "as estruturas corporativas da época da guerra tenham fracassado em obter expressão institucional duradoura" ao contrário do que ocorreu na Europa Ocidental, durante a guerra, os conflitos trabalhistas indicavam outras possibilidades de futuro:

O poder da elite no topo do aparato de mobilização era repetidamente desafiado pelas insurgências de baixo para cima que buscavam se aproveitar da demanda sem precedente por trabalho enquanto, ao mesmo tempo, atualizavam o etos pluralista, social-patriótico que era uma ideologia quase oficial da frente doméstica na Segunda Guerra Mundial. ${ }^{7}$

$\mathrm{Na}$ Europa Ocidental, um dos principais cenários do confronto, a Segunda Guerra Mundial criou condições inéditas para a apropriação do patriotismo por parte da esquerda, que cumpriu papel fundamental na resistência ao Eixo. Desde a Primeira Guerra Mundial, tornara-se evidente que as esmagadoras demandas geradas pela mobilização de milhões de soldados por vários anos e pelo volume de armamento e insumos utilizados nos combates tensionava a força de trabalho, gerando ondas de ativismo operário e fortalecimento dos sindicatos. ${ }^{8} \mathrm{~A}$ guerra também transformava a composição da força de trabalho, acelerando, por exemplo, a incorporação de mulheres à indústria.

5 SKOCPOL, Theda. Protecting soldiers and mothers: the political origins of social policy in the United States. Cambridge: Harvard University Press, 1992.

6 GALBRAITH, John Keneth. A era da incerteza. São Paulo: Pioneira, 1980. p. 220.

7 LICHTENSTEIN, Nelson. Class Politics and the State during World War Two. International Labor and Working-Class History, v. 58, p. 261-274, oct. 2000.

8 Leo Lucassen destaca que "The Great War has, as a pressure cooker, exerted a profound influence on many social developments in the 20th century". Cf. LUCASSEN, Leo. The Great War as motor of social change. Disponível em: https://socialhistory.org/en/collections/first-world-war. Acesso em: 13 mar. 2019. 
As concepções de política econômica também se alteravam, já que, após "cem anos de paz", as grandes guerras do século XX não mais seriam "business as usual". Polanyi chamou atenção para a vinculação entre equilíbrio de poder, mercado autorregulável, estado liberal e padrão ouro. ${ }^{9} \mathrm{~A}$ ruptura do primeiro desses alicerces da ordem mundial do século XIX viria abalar os demais. A Grã-Bretanha, baluarte do equilíbrio fiscal, não voltou a ser a mesma depois de travar duas guerras muito além dos seus meios. O planejamento econômico centralizado tornava-se impositivo, compreendeu Lenin ao extrair da economia de guerra alemã lições aplicadas ao Comunismo de Guerra. Se em 1939, apenas Alemanha e URSS tinham mecanismo para controle físico da economia, ao longo da Segunda Guerra Mundial as democracias ocidentais os implantaram com eficácia superior. Consequentemente, as crianças da Grã-Bretanha saíam da guerra com saúde melhor do que entraram, os salários de trabalhadores estavam mais altos e a sensação de justiça social fortalecida. ${ }^{10} \mathrm{Em}$ diversos países, portanto, a Segunda Guerra forjou uma cultura de solidariedade baseada em uma ética de sacrifícios compartilhados, que se somou à compreensão do bem-estar da população como fator de defesa nacional, criando condições para um pacto político amplo e consistente em favor de reformas redistributivas. ${ }^{11}$

Num balanço mais abrangente sobre o lugar das guerras na história social e política, Eley destaca que "os principais avanços da democracia europeia geral no começo do século XX dependeram das condições de colapso ou transformação social produzidas pela guerra". Ondas de expansão de direitos surgiram em contextos em que o Estado ampliava suas "demandas sobre a sociedade, seus recursos e sua população territorial", enquanto "a militarização da vida pública" tornava-o "menos suscetível à transparência e ao controle". Mas, ao mesmo tempo, a guerra produziu "novas capacidades democráticas, que se tornaram organizadas num impressionante rearranjo legal, institucional e político no pós-guerra". O esforço de guerra "legitimou a voz de todos aqueles grupos que desejam se situar dentro do consenso", tais como a classe trabalhadora organizada, as mulheres, os jovens e os soldados. A síntese dessas contradições se expressa na expressão "descontar o cheque patriótico", que traduzia "a expectativa popular de reformas sociais e políticas substantivas em retorno pelos sacrifícios demandados

9 POLANYI, Karl. The great transformation: the political and economic origins of our time. Boston: Beacon Press, 2001.

10 HOBSBAWM, Eric. Era dos extremos: o breve século XX, 1914-1991. São Paulo: Companhia das Letras, 1996. p. 144-177.

11 ELEY, Geoff. Forjando a democracia: a história da esquerda na Europa, 1850-2000. São Paulo: Editora Fundação Perseu Abramo, 2005. p. 307-347. 
pela mobilização de guerra”. A memória coletiva do pós-guerra, que contrastava a "Guerra do Povo" à vergonhosa passividade diante da crise dos anos 1930, teria sustentado a "síntese keynesiana do Estado de Bem-Estar 'do berço ao túmulo", a partir do entendimento de que o "igualitarismo e a solidariedade social necessários para a vitória" precisariam ser mantidos posteriormente por meio de "políticas sociais igualitárias em tempos de paz". ${ }^{12}$

Por razões como essas, o estudo do impacto da Segunda Guerra Mundial sobre a classe trabalhadora em diversas partes do mundo tem sido crescente. $O$ número especial da International Labor and Working-Class History dedicado ao tema em $1990^{13}$ destacava que as invocações patrióticas ao "sangue, suor e lágrimas" de Churchill são universalmente conhecidas como expressão do "vasto esforço na frente doméstica necessária para a prática da guerra total", enquanto "o papel central desempenhado pela população trabalhadora" permaneceu durante muito tempo inexplorado". ${ }^{14}$ Dez anos depois, novo dossiê do mesmo periódico tornava a abordar o tema ${ }^{15}$ em contextos tão distintos como a União Soviética, ${ }^{16}$ o Terceiro Reich ${ }^{17}$ e o Leste Asiático. ${ }^{18}$

Peter Alexander comparou o impacto da economia de guerra sobre a relação entre raça e classe nos Estados Unidos e África do Sul. Nos dois casos, "como consequência da industrialização e da resistência relacionados à guerra, os trabalhadores negros aderiram aos movimentos trabalhistas em massa". Em ambos os países, "esse foi um período de extenso conflito industrial e ascensão na filiação aos sindicatos" e "a classe trabalhadora foi transformada, tornando-se maior, mais jovem, mais negra e mais feminina". Também foi similar o aquecimento do mercado de trabalho, aumentando a autoconfiança dos ativistas, e a inflação acelerada, com a consequente pressão por melhorias salariais resultando em greves geralmente bem-sucedidas. Acordos entres sindicalistas, governo e empregadores, embora visassem diminuir as paralisações, estimularam a sindicalização, o que fomentou

12 ELEY, Geoff. War and the Twentieth-Century State. Dædalus, v. 124, n. 2, p. 155-174, spring 1995 (citações p. 163-169).

13 International Labor and Working-Class History, n. 38, fall 1990. [dossier] The Working Class in World War II.

14 GRUBER, Helmut. Editors' Remarks. International Labor and Working-Class History, n. 38, p.12 , fall 1990.

15 International Labor and Working-Class History, v. 58, oct. 2000. [dossier] Wartime Economies and the Mobilization of Labor.

16 BARNES, Steven All for the Front, All for Victory! The Mobilization of Forced Labor in the Soviet Union during World War Two. International Labor and Working-Class History, v. 58, p. 239-260, oct. 2000.

17 HERBERT, Ulrich. Forced Laborers in the Third Reich: An Overview. International Labor and Working-Class History, v. 58, p.192-218, oct. 2000.

18 SMITH, Donald. Beyond The Bridge on the River Kwai: Labor Mobilization in the Greater East Asia Co-prosperity Sphere. International Labor and Working-Class History, v. 58, p. 219-238, oct. 2000. 
movimentos reivindicatórios espontâneos. Nos dois países, embora muitos militantes brancos ainda fossem racistas, ocorreram greves multirraciais, gerando um nível mais alto de organização entre trabalhadores negros e uma tendência mais igualitária entre trabalhadores brancos. As diferenças, porém, são igualmente marcantes. Nos Estados Unidos, a Ordem Executiva 8802 baniu as práticas de segregação racial no processo de contratação; já a Medida 145 da África do Sul reforçou as divisões raciais. Nesse processo, o sindicalismo sul-africano foi severamente enfraquecido, e as perspectivas para uma unidade operária interracial no pós-guerra se reduziram substantivamente. ${ }^{19}$

A relação da América Latina com a guerra foi de natureza e intensidade absolutamente distintas do que ocorreu nas principais nações beligerantes. Para Centeno, de forma geral conflitos militares desempenharam papel menos relevante na formação dos estados nacionais na região do que em outras partes do planeta. Apesar da participação do Brasil na Segunda Guerra, "mesmo em 1945, parece ter havido pouco esforço para glorificar" a vitória dos aliados. ${ }^{20}$ Perry Anderson também vê a América Latina carente do "gigantesco catalizador" que as duas guerras mundiais representaram para o movimento operário europeu, "radicalizando trabalhadores apolíticos, multiplicando o número de sindicatos, levando partidos da classe trabalhadora ao poder e desencadeando revoluções sociais". ${ }^{21}$

O exemplo sul-africano mencionado acima, entretanto, oferece um paralelo interessante para relativizar a avaliação do impacto do esforço de guerra sobre os trabalhadores em áreas cujo envolvimento em combates foi relativamente pequeno. Em seu livro sobre os mineiros de carvão do Chile, Jody Pavilack ressalta que a guerra marcou o ápice de um processo de conquista de direitos do trabalho e de protagonismo político operário que já vinha se desenvolvendo sob os governos das Frentes Populares desde o início da década de 1930. Hobsbawm já havia destacado que aquela foi uma conjuntura única, na qual a polarização ideológica entre capitalismo e comunismo ficava temporariamente em segundo plano diante do conflito entre Aliados e Eixo. Pavilack exemplifica isso ao relatar o discurso do vice-presidente norte-americano Henry Wallace na cidade mineira de Lota (Chile),

19 ALEXANDER, Peter. South African and US Labour in the Era of World War II: Similar Trends and Underlying Differences. In: HALPERN, Rick; MORRIS, Jonathan (ed.) American Exceptionalism? US Working-Class Formation in an International Context. New York: St. Martin's Press, 1997. p. 244-270.

20 CENTENO, Miguel. Blood and debt: war and the nation-state in Latin America. Pennsylvania: Pennsylvania State University Press, 2002.

21 ANDERSON, Perry. The Common and the Particular. International Labor and Working-Class History, v. 36, p. 31-36, fall 1989. 
conhecido reduto comunista, saudando os trabalhadores locais e seus líderes como "soldados da democracia". ${ }^{22}$

Como situar o Brasil nesse debate global sobre a relação entre guerra total e transformações no mundo do trabalho?

A importância da Segunda Guerra Mundial para o país não pode ser medida pelos 25 mil soldados enviados para combater na Itália, dos quais 471 tombaram. ${ }^{23}$ Nem mesmo pelos 1.074 mortos resultantes do torpedeamento de navios por submarinos alemães na costa brasileira. São números pálidos num conflito que causou a morte de cerca de 60 milhões de pessoas. O envolvimento na conflagração global, entretanto, produziu transformações que moldariam o curso da história brasileira na segunda metade do século $X X$.

McCann identificou na análise da situação internacional preparada pelo ministro de Relações Exteriores Oswaldo Aranha para o encontro secreto de Getúlio Vargas com Franklin Roosevelt em Natal, em 1943, "um resumo das políticas externas e domésticas do Brasil nas décadas seguintes". A "cooperação segura e íntima com os Estados Unidos" seria condição para o desenvolvimento de poder marítimo e aéreo visando consolidar a superioridade brasileira na América do Sul. Isso exigia o desenvolvimento da indústria pesada e de guerra, o fomento a indústrias essenciais à reconstrução mundial, a expansão do sistema de ferrovias e rodovias e a exploração de combustíveis essenciais. ${ }^{24}$

Esse era um cenário radicalmente novo. Nas décadas anteriores, os gestores da economia brasileira haviam buscado em vão o apoio de Washington a acordos comerciais que assegurassem os dólares necessários às importações do país e investimentos para alavancar o seu desenvolvimento industrial. A súbita disposição em conceder ao Brasil o status de aliado estratégico surgiu apenas em 1940, quando a inteligência britânica convenceu as autoridades norte-americanas de que os alemães poderiam cruzar a linha Dakar-Natal, estabelecer bases no Nordeste brasileiro e fomentar uma onda de golpes pró-Eixo na América do Sul. Os americanos fortaleceram a política de boa vizinhança (cooperação interestatal, cultural,

22 PAVILACK, Jody. Mining for the nation: the politics of Chile's coal communities from the Popular Front to the Cold War. Pennsylvania: Pennsylvania State University Press, 2011.

23 Cerca de 12 mil sofreram ferimentos de guerra, acidentes ou enfermidades que viriam a causar posteriormente a morte de outros dois mil.

24 MCCANN, Frank. Brazil and World War II: the Forgotten Ally. What did you do in the war, Zé Carioca? Estudios interdisciplinarios de America Latina y el Caribe, v. 6, n. 2, p. 35, jan. 1995. 
econômica etc.), mas também planejaram a "Operation Pot of Gold", uma "invasão preventiva" de 100 mil soldados que seria desencadeada caso as negociações com Vargas não prosperassem. ${ }^{25}$

A influência econômica alemã no país crescera nos anos anteriores. O colapso das exportações de café, fonte básica de divisas internacionais, obrigara Vargas inicialmente desvalorizar a moeda em $110 \%$, prejudicando a indústria nacional. Entre 1933 e 1936, déficits planejados e controlados geraram um crescimento médio de 8\% (13,4\% no setor industrial), mas a política de taxas de câmbio diferenciadas para importações e remessa de lucros foi condenada por norte-americanos e britânicos, que condicionaram a renovação dos créditos à "liberalização" da economia brasileira.

Já as negociações com a Alemanha atendiam de forma mais equilibrada aos interesses agroexportadores e industriais. Os "marcos de compensação", propostos em 1934 pelo ministro da economia alemão Hjalmar Schacht, eram depositados em conta do Banco do Brasil no Reichsbank, sem as perdas decorrentes da conversão em dólar e utilizados na aquisição de maquinário e insumos, além dos armamentos para as obsoletas Forças Armadas brasileiras que os norte-americanos relutavam em fornecer. Entre 1934 e 1939, a participação alemã nas exportações brasileiras cresceu de 12 a 20\%, a norte-americana apenas de 21,2 para 25,5\%, enquanto a britânica caía de 19,4 para 10,9\%. ${ }^{26}$ Em 1941, o cônsul norte-americano em Recife atribuía as simpatias pelos nazistas no Nordeste brasileiro à lembrança da "prosperidade" e "bons tempos" trazidos pelo Marco Aski (Aüslander Sonderkonten Für Inlandbezahlungen), que garantia a venda a bom preço de mercadorias como o algodão, além do acesso aos cobiçados produtos industrializados alemães. ${ }^{27}$ As filiais de empresas alemãs e/ou teuto-brasileiras articulavam redes "germanófilas" por todo o país, fomentaram os grupos nazistas e sustentaram a espionagem comercial, política e militar alemã. ${ }^{28}$ Clubes alemães rivalizavam com os britânicos como espaços de sociabilidade da elite local em várias cidades. Em 1936, as bandeiras do Brasil e do Terceiro Reich tremulavam na capa da revista do Deutscher Klub de Pernambuco. ${ }^{29}$

25 MCCANN, Frank. Brazil and World War II: the Forgotten Ally. What did you do in the war, Zé Carioca? Estudios interdisciplinarios de America Latina y el Caribe, v. 6, n. 2, p. 36, jan. 1995.

26 ABREU, Marcelo de Paiva. The Brazilian Economy, 1930-1980. In: BETHELL, Leslie (ed.). The Cambridge History of Latin America. Cambridge: Cambridge University Press, 2008. p. 281-394.

27 NATIONAL ARCHIVES AND RECORDS ADMINISTRATION (NARA). Walter J. Linthicum (American Consul) to Jefferson Caffery (American Ambassador). 11 fev. 1941. Record Group 84 - Post Files. Entry 2154, Political Reports, compiled 1938-1949 (Recife), Box 1.

28 HILTON, Stanley. Suástica sobre o Brasil: a história da espionagem alemã no Brasil, 1939-1944. Rio de Janeiro: Civilização Brasileira, 1977.

29 NATIONAL ARCHIVES AND RECORDS ADMINISTRATION (NARA). Record Group 226 - Office of Strategic Services [OSS]. A publicação continha um artigo de Walter Gross, "líder de política racial" do Partido Nacional Socialista dos Trabalhadores Alemães sobre Politische und geistige Revolution 
Enquanto isso, as relações com os Estados Unidos tornavam a se agravar no contexto da recessão norte-americana de 1937, acumulando uma deterioração nos termos de troca de $48 \%$ desde 1928. A situação começou a se alterar justamente com o início da guerra, em 1939. O governo brasileiro volta a controlar o câmbio, dessa vez sem oposição norte-americana. Ao contrário, um novo acordo foi fechado para o pagamento da dívida externa, e, em 1940, estabeleceu-se o "Inter-American Coffee Agreement". Em 1942, os Acordos de Washington estenderam as políticas de cotas fixas de aquisição de produtos brasileiros à borracha, cacau, algodão, castanha-do-Pará, minério de ferro, diamantes industriais, mica, quartzo, juta e mamona, dentre outros produtos, muitos dos quais jamais exportados anteriormente. Apesar do aumento da importação de manufaturados norte-americanos, o bloqueio do comércio com a Europa abria uma janela para o crescimento industrial brasileiro.

Vargas explorou o conflito mundial para viabilizar o início da construção da Usina Siderúrgica de Volta Redonda, visando tornar o país, detentor das maiores reservas mundiais de minério de ferro, um grande produtor de aço. Durante a neutralidade, o Brasil discutira o projeto com os alemães, mas o bloqueio britânico do Atlântico tornara a parceria inviável. Os norte-americanos recusaram a proposta de Vargas para que eles realizassem investimento direto no empreendimento e assumissem sua gestão, mas ofereceram apoio financeiro e técnico norte-americano decisivo para a criação da siderúrgica como empresa estatal. ${ }^{30}$

A partir dos acordos de 1942, o suprimento às demandas de guerra gerou crescimento médio de $6,4 \%$ até 1945 , com a indústria crescendo $9,9 \%$ ao ano. O poder de captação do Estado foi fortalecido com aumento da arrecadação de impostos sobre consumo e renda, além da emissão de bônus de guerra. $\mathrm{O}$ acúmulo de reservas estrangeiras possibilitou uma negociação definitiva da dívida externa em 1943, com uma redução em $50 \%$ do seu valor nominal. O Estado assumiu o controle sobre águas, minérios, indústrias estratégicas, bancos e setor de seguros. Empresas e propriedades pertencentes aos governos do Eixo foram expropriadas, incluindo poderosos bancos alemães e italianos. A Itabira Iron Company foi transformada na estatal Companhia Vale do Rio Doce, encerrando décadas de conflito com investidores norte-americanos e britânicos. Os EUA financiaram a construção da ferrovia ligando as gigantescas minas de ferro de Itabira ao porto de Vitória, no Espírito Santo. Outras indústrias estatais estratégicas criadas no período

("Revolução política e intelectual").

30 ABREU, Marcelo de Paiva. The Brazilian Economy, 1930-1980. In: BETHELL, Leslie (ed.). The Cambridge History of Latin America. Cambridge: Cambridge University Press, 2008. p. 281-394. DINIUS, Oliver. Brazil's steel city: developmentalism, strategic power, and industrial relations in Volta Redonda, 1941-1964. Stanford: Stanford University Press, 2010. Chapter 1. 
incluem a Companhia Nacional de Álcalis ${ }^{31}$ e a Fábrica Nacional de Motores. ${ }^{32} \mathrm{~A}$ gestão da economia se fortaleceu com a criação do Departamento de Administração Pública, que modernizou o sistema orçamentário, do Conselho Técnico Econômico e Financeiro e da Coordenação de Mobilização Econômica. No plano da política social, esse foi também o período da criação da Consolidação das Leis do Trabalho, dos institutos de Previdência Social e da consolidação da Justiça do Trabalho.

As relações do governo Vargas com os EUA, entretanto, se alteraram rapidamente. Definido o conflito em favor dos aliados a partir de 1943, os norte-americanos se mostraram menos generosos. Os custos de produção subiam, mas os EUA resistiam a reajustar os preços do café. O racionamento de importações pelo Brasil em 1944 gerou novos ruídos na aliança. No cenário político, a relação de Vargas com os norte-americanos deteriorava-se aceleradamente, e o embaixador Adolf Berle viria a desempenhar papel relevante na queda do ditador. Porém, a breve e peculiar experiência de consolidação de um projeto político nacionalista latino-americano em aliança com os EUA produziria consequências de longo prazo. A natureza da guerra estabelecera definitivamente o vínculo entre industrialização e soberania nacional. Já a "barganha nacionalista" de Vargas esboçara o caminho a ser perseguido na política externa a fim de viabilizar esse objetivo nacional. ${ }^{33}$

Mas de que modo os trabalhadores brasileiros vivenciaram esse período de mudanças aceleradas? Em que medida as conexões entre defesa, política externa, política econômica e concepções de cidadania verificadas em outros contextos também ocorreram no Brasil?

Se compararmos o Brasil em 1940 - dez anos após a chegada de Vargas ao poder - com o que ocorria no período em várias partes da América Latina ${ }^{34}$, chama

31 IANNI, Otávio. Estado e planejamento econômico no Brasil. Rio de Janeiro: Editora da UFRJ, 2009.

32 RAMALHO, José Ricardo. Estado-patrão e luta operária: o caso FNM. São Paulo: Paz e Terra, 1989.

33 SEITENFUS, Ricardo. O Brasil de Getúlio Vargas e a formação dos blocos, 1930-1942: o processo do envolvimento brasileiro na II Guerra Mundial. São Paulo: Companhia Editora Nacional, 1985. . . O Brasil vai a guerra: o processo do envolvimento brasileiro na Segunda Guerra Mundial. Barueri: Manole, 2003. MCCANN, Frank. The Brazilian-American alliance, 1937-1945. Princeton: Princeton University Press, 1974. VIZENTINI, Paulo. Relações internacionais do Brasil: de Vargas a Lula. São Paulo: Editora Fundação Perseu Abramo, 2003.

34 Processos de incorporação da mobilização do operariado organizado ao sistema político, combinadas com um papel ativo de regulação estatal nas condições de trabalho, vinham ocorrendo ao menos desde a Primeira Guerra Mundial em várias partes da América Latina, acentuando-se em muitos casos nos anos 1930 (não sem desvios e retrocessos). Alguns exemplos: TORRE, Juan Carlos (1990). La vieja guardia sindical y Perón: sobre los orígenes del peronismo. Buenos Aires: Editorial Sudamericana, Instituto Torcuato di Tella, 2006. MIDDLEBROOK, Kevin J. The paradox 
atenção a falta de mobilização de massas por parte do Estado, assim como de partidos ou movimentos com bases operárias visando lhe dar sustentação política. $\mathrm{Na}$ ausência de uma estrutura nacional integrada, os sindicalistas varguistas não desempenhavam qualquer papel significativo no sistema político. A própria legislação social e trabalhista possuía caráter fragmentado e baixa efetividade. $O$ início da ditadura do Estado Novo, em 1937, aprofundou esse quadro, pois com os comunistas fora dos sindicatos, eles sofreram um esvaziamento brutal, dada a baixa capacidade organizativa dos apoiadores do governo.

A percepção do significado da guerra total, entretanto, alterou a visão da cúpula do Estado Novo sobre a relação entre as atividades civis e militares, com desdobramentos em relação à política trabalhista. Osvaldo Cordeiro de Farias, interventor federal no Rio Grande do Sul e posteriormente general da Força Expedicionária Brasileira sintetizou essa percepção ao destacar que, a partir de 1939, "a guerra passou a atingir o país como um todo. O inimigo bombardeia instalações industriais e fornecedoras de material, destrói os sistemas de comunicação e transportes e ataca a população indefesa para desmoralizá-la psicologicamente." 35

Esse novo tipo de guerra produzia a identificação do trabalho manual civil com a defesa nacional (os "soldados da produção"), ${ }^{36}$ gerando dinâmicas contraditórias de inclusão e exclusão dos trabalhadores. De um lado, a legislação de mobilização econômica, tal como o Decreto-Lei $n^{\circ} 4.639$, de 31 de agosto de 1942, possibilitava a suspensão de direitos trabalhistas e civis. ${ }^{37}$ De outro, a imagem da fábrica como trincheira possibilitava a reapropriação do discurso nacionalista como instrumento de defesa de melhores condições de trabalho e de remuneração. Se os trabalhadores se sacrificavam pela nação, mereciam uma vida digna. ${ }^{38}$ Ao mesmo tempo, racionamento, escassez, especulação, mercado negro etc. geravam a revolta

of revolution: labor, the state, and authoritarianism in Mexico. Baltimore: Johns Hopkins University Press, 1995. PAVILACK, Jody. Mining for the nation: the politics of Chile's coal communities from the Popular Front to the Cold War. Pennsylvania: Pennsylvania State University Press, 2011.

35 CAMARGO, Aspásia; GOÉS, Walter de. Meio século de combate: dialogo com Cordeiro de Farias. Rio de Janeiro: Nova Fronteira, 1981. p. 407-409.

36 PUREZA, Fernando. Economia de guerra, batalha da produção e soldados-operários: o impacto da Segunda Guerra Mundial na vida dos trabalhadores de Porto Alegre (1942-1945). Dissertação (Mestrado em História) - Universidade Federal do Rio Grande do Sul, Porto Alegre, 2009.

37 PAOLI, Maria Célia. O trabalhador urbano na fala dos outros. In: LOPES, José Sérgio Leite (ed.). Cultura e Identidade Operária. Rio de Janeiro: Museu Nacional/Marco Zero, 1987. p. 53-101. WOLFE, Joel. Working women, working men: São Paulo and the rise of Brazil's industrial working class, 1900-1955. Durham: Duke University Press, 1993. Wolfe argumenta corretamente que a militarização do trabalho restringiu ainda mais a possibilidade de sindicatos oficiais atuarem como mecanismo de representação das demandas dos trabalhadores no período. Ignorou, porém, as possibilidades abertas pelas dinâmicas contraditórias do nacionalismo antifascista descritas acima (p. 94-124).

38 COSTA, Hélio da. Em busca da memória. São Paulo: Scritta, 1995. 
popular contra os "tubarões" que se aproveitaram do sacrifício imposto à nação em guerra para obter lucros extraordinários, fortalecendo a consciência de classe. ${ }^{39}$

Paralelamente, os grandes projetos e as demandas produtivas do Brasil e de seus aliados norte-americanos desencadearam migrações internas em grande escala, geradas por uma série de novos processos econômicos. A aceleração da produção industrial atraía trabalhadores do campo para a cidade e das regiões menos industrializadas para as mais industrializadas. Milhares de nordestinos foram recrutados e deslocados para a Amazônia para se tornarem "soldados da borracha"40. Numerosas massas de trabalhadores também se deslocavam para regiões até então desabitadas, nas quais eram construídas grandes plantas industriais como a Usina Siderúrgica de Volta Redonda, ${ }^{41}$ a Fábrica Nacional de Motores em Xerém, na Baixada Fluminense, ${ }^{42}$ a Nitro Química em São Miguel Paulista, na periferia da cidade de São Paulo, ${ }^{43}$ e as minas de manganês de Serra do Navio, no Amapá, ${ }^{44}$ o mesmo ocorrendo com os aeroportos estabelecidos no Norte e Nordeste do país pelo Airport Development Program, levado a cabo pela Pan American Airlines. ${ }^{45}$

Ocorria também uma importante inversão de sinal no que diz respeito às concepções sobre raça. Imigrantes alemães, vistos até então como uma importante contribuição ao "branqueamento" do país, tornavam-se a expressão maior do inimigo externo ("o Eixo") e interno ("a Quinta Coluna"). Nesse processo, a "comunidade imaginária" da nação ${ }^{46}$ era reforçada e redefinida, com políticas voltadas à valorização da "cultura popular", depurada de seus aspectos "desordeiros". ${ }^{47}$

Militantes comunistas relatam que a campanha em favor do ingresso do país na guerra ajudou a romper o isolamento da esquerda no cenário político nacional após as intensas ondas repressivas de 1935 e 1937. Para o então estudante baiano

39 PAOLI, Maria Célia. O trabalhador urbano na fala dos outros. In: LOPES, José Sérgio Leite (ed.). Cultura e Identidade Operária. Rio de Janeiro: Museu Nacional/Marco Zero, 1987. p. 53-101.

40 SECRETO, María Verónica. Soldados da borracha: trabalhadores entre o sertão e a Amazônia no governo Vargas. São Paulo: Editora Fundação Perseu Abramo, 2007. GARFIELD, Seth. A Amazônia no imaginário norte-americano em tempo de guerra. Revista Brasileira de História, v. 29, n. 57, p. 19-65, 2009.

41 DINIUS, Oliver. Brazil's steel city: developmentalism, strategic power and industrial relations in Volta Redonda, 1941-1964. Stanford: Stanford University Press, 2010.

42 RAMALHO, José Ricardo. Estado-patrão e luta operária: o caso FNM. São Paulo, Paz e Terra, 1989.

43 FONTES, Paulo. Um Nordeste em São Paulo: trabalhadores migrantes em São Miguel Paulista (1945-1966). Rio de Janeiro: Editora FGV, 2008.

44 PAZ, Adalberto. Os mineiros da floresta: sociedade e trabalho em uma fronteira de mineração industrial amazônica (1943-1964). Dissertação (Mestrado em História) - Universidade Estadual de Campinas, Campinas, 2011.

45 HERMAN, Rebecca. In Defense of Sovereignty: Labor, Crime, Sex and Nation at U.S. Military Bases in Latin America, 1940-1947. PhD (History) - University of California, Berkeley, 2014. p. 305.

46 ANDERSON, Benedict. Comunidades imaginadas: reflexões sobre a origem e a difusão do nacionalismo. São Paulo: Companhia das Letras, 2008.

47 PARANHOS, Adalberto. O roubo da fala: origens da ideologia do trabalhismo no Brasil. São Paulo: Boitempo, 1999. 
João Falcão, a declaração de guerra ao Eixo resultou de um "contínuo movimento de massas que perdurou por mais de dois anos" ${ }^{48}$ Militantes comunistas atuantes em centros industriais da Baixada Fluminense, como Magé, exultavam diante do novo cenário - propiciado pela guerra - de maior contato face a face com trabalhadores, industriais, governantes e variados setores da sociedade, que lhes possibilitava estabelecer "relações de classe de novo tipo" ${ }^{49}$ Já no Rio Grande do Sul, o metalúrgico Eloy Martins realizava trabalho de base nas oficinas do Estado, a partir da leitura coletiva das notícias da guerra após o almoço:

Nosso trabalho foi tão eficiente que estruturamos ali, assim que o partido veio para a legalidade, uma célula com mais de 20 simpatizantes. O fresador, intransigente defensor de Hitler, se tornou simpatizante da causa socialista. ${ }^{50}$

Além de possibilitar a instrumentalização de um assunto candente pelo proselitismo da esquerda, o envolvimento do país no cenário de guerra desencadeava ou catalisava importantes transformações sociopolíticas. Em Porto Alegre, na época o terceiro polo industrial do Brasil, a maioria das indústrias pertencia a teuto-brasileiros, gerando forte intersecção entre etnicidade e classe. Não se tratava apenas do preconceito contra trabalhadores "brasileiros" (de sobrenome luso e características físicas associadas à miscigenação com indígenas e/ou afrodescendentes). A estrutura institucional da "colônia alemã" (clubes, escolas, jornais, igrejas, consulado da Alemanha etc.) amplificava a influência do empresariado teuto-brasileiro sobre um amplo espectro da vida social local. O domínio da língua e o vínculo a famílias de origem alemã poderiam abrir portas para empregos em grandes empresas com políticas assistenciais abrangentes, bem como para a mobilidade social ascendente dentro ou fora das fábricas. $O$ ingresso do Brasil na guerra impacta profundamente essa configuração social local. Uma indicação simbólica foi a reação popular contra o torpedeamento de navios brasileiros por submarinos alemães, em agosto de 1942. No distrito industrial, as placas das avenidas "Alemanha" e "Itália" foram arrancadas pela multidão e substituídas por outras com os nomes de duas embarcações afundadas. $\mathrm{O}$ ato foi posteriormente oficializado pela prefeitura da cidade. As lojas Renner, vinculadas ao maior complexo industrial do estado e exemplo de "capitalismo de bem-estar", foram apedrejadas. ${ }^{51}$

48 FALCÃO, João. O Brasil e a Segunda Guerra Mundial: testemunho e depoimento de um soldado convocado. Brasília: Editora UnB, 1998. p. 21.

49 RIBEIRO, Felipe. A foice, o martelo e outras ferramentas de ação política: os trabalhadores rurais e têxteis de Magé/RJ (1956-1973). Tese (Doutorado em História, Política e Bens Culturais) Fundação Getúlio Vargas, Rio de Janeiro, 2015. p. 113-114.

50 MARTINS, Eloy. Um depoimento político. Porto Alegre: edição do autor, 1989. p. 72-73.

51 FORTES, Alexandre. Nós do quarto distrito: A classe trabalhadora porto-alegrense e a era 
Se os descendentes de alemães se concentravam no Sul, a presença germânica na atividade econômica atingia outras regiões do país, fortalecida pelo estreitamento das relações comerciais entre os dois países entre 1934 e 1939. Na Bahia, as mais tradicionais fábricas de charutos do Recôncavo, Dannemann e Suerdieck, eram propriedade de "súditos do Eixo" (de fato, teuto-brasileiros), e também se tornaram alvos de ataques das massas populares após o afundamento de navios brasileiros pela marinha alemã. ${ }^{52}$

O maior grupo industrial de Pernambuco, a Tecelagem Paulista, pertencia à família Lundgren, imigrantes suecos de ascendência materna germânica, que estiveram sob forte vigilância da espionagem nacional e internacional devido ao seu envolvimento com o nazismo. Porta-vozes do empresariado têxtil nordestino, os Lundgren, em 1939, recorriam à suposta inferioridade racial dos seus trabalhadores para demandar medidas protecionistas:

Nas populações do Norte predominam os elementos primitivos que entram no seu amalgamento - o branco, o negro e o indígena -, formando as chamadas raças de mamelucos e mestiços, quando no Sul, em virtude dos movimentos migratórios, a influência tem sido benéfica na formação da raça meridional do país..$^{53}$

Após a guerra, os argumentos abertamente racistas são abandonados e a baixa produtividade da companhia passou a ser atribuída à obsolescência tecnológica. A recusa em cumprir as leis trabalhistas também foi substituída por estratégias jurídicas visando reduzir seu impacto sobre os lucros e sobre o poder da empresa em relação a sua mão de obra.

Pernambuco oferece um palco privilegiado para analisarmos como a guerra em nome da democracia, contra um movimento expansionista baseada em doutrinas de superioridade branca, redefiniu os discursos sobre relações raciais e suas conexões com as relações de classe. Um artigo publicado em 1942 causou a detenção do célebre sociólogo Gilberto Freyre por dois delegados de polícia "abertamente simpáticos ao Eixo". No texto, Freyre denunciava "falsos religiosos" que se dedicavam à difusão "de doutrinas ferozmente etnocêntricas, anticristãs e antibrasileiras", e concluía:

Numa época em que os ódios políticos e os orgulhos de raças sobrepõem-se a tudo mais, quebrando até em religiosos a fidelidade aos ideais cristãos de fraternidade humana, os povos, como o

Vargas. Rio de Janeiro/Caxias do Sul: Garamond Universitária/EDUCS, 2004. p. 177-236. Capítulo 5.

52 FALCÃO, João. O Brasil e a Segunda Guerra Mundial: testemunho e depoimento de um soldado convocado. Brasília: Editora UnB, 1998.

53 LOPES, José Sérgio Leite. A tecelagem dos conflitos de classe na "cidade das chaminés". São Paulo: Marco Zero, 1988. p. 295. 
brasileiro, cuja organização inteira descansa sobre a mestiçagem, sobre os direitos do preto, do indígena, do mestiço, aos mesmos privilégios do branco, precisam de estar vigilantes. ${ }^{54}$

Os "falsos religiosos" eram ex-franciscanos alemães responsáveis pela propaganda nazista justamente na Companhia de Tecidos Paulista estudada por Leite Lopes. ${ }^{55}$ Em novembro de 1942, 23 dos 47 funcionários alemães da empresa foram detidos pela polícia política e enviados a um "campo de concentração" construído pela própria empresa a 60 quilômetros de Recife, onde ficaram detidos até agosto de 1945. A delegação do poder de Estado à companhia para lidar com a questão surpreende pela abundância de evidências de envolvimento dos seus proprietários com o nazismo. ${ }^{56}$

Mas não era apenas a repressão estatal e patronal que atingia os até então privilegiados membros da comunidade alemã nordestina, agora identificados como expressão da "Quinta Coluna". Waldemar Soares Ribeiro, morador da cidade paraibana de Rio Tinto, onde os Lundgren possuíam sua segunda maior unidade industrial, tinha nove anos de idade quando a guerra acabou. Treze dias após o fim do conflito, recorda-se de ter visto milhares de operários da fábrica de tecidos invadirem os chalés dos alemães ocupantes de cargos de chefia e administração, "quebrando tudo e exigindo que os estrangeiros fossem deportados". ${ }^{57}$

Ações populares de massas movidas por sentimentos nacionalistas, com o apoio (ou ao menos a complacência) de setores do aparelho de Estado, eram novidade no cenário político brasileiro, ao menos em escala nacional. A partir de 17 de agosto de 1942, quando diversas embarcações foram afundadas pelo submarino alemão U-507 na costa brasileira, resultando em 551 mortes, essas ações de massas antieixo se multiplicaram por todo o país. Desencadeadas pelo envolvimento do Brasil na guerra, inauguraram uma nova era na presença das massas no processo político, acelerando a implementação de uma agenda de transformações econômicas e sociais que, até então, avançara de forma lenta e descontínua.

Os trabalhadores, que haviam sido "convidados" ao sacrifício na guerra, começaram a descontar seu "cheque patriótico", diante do "esforço de guerra"

54 FREYRE, Gilberto. O exemplo de Ibiapina. Diário de Pernambuco, Recife, 11 jun. 1942. NATIONAL ARCHIVES AND RECORDS ADMINISTRATION (NARA). Reports, 1938-49, Box 1.

55 NATIONAL ARCHIVES AND RECORDS ADMINISTRATION (NARA). Secretaria de Segurança Pública. Denúncia sobre supostas atividades de religiosos estrangeiros em Pernambuco. Diligências da Delegacia de Ordem Política e Social para esclarecimentos. Record Group 84 - Post Files, Entry 2154 (Recife: Political Reports, 1938-1949), Box 1.

56 PERAZZO, Priscila. Prisioneiros da guerra: os "súditos do Eixo" nos campos de concentração brasileiros (1942-1945). São Paulo, Humanitas/Imprensa Oficial, 2009. p. 112-132.

57 CHAVES, Frutuoso Lembranças do nazismo na Paraíba. Jornal do Commercio, Recife, 20 nov. 2000. Disponível em: http://www2.uol.com.br/JC/_2000/2011/cp2011_1.htm. Acesso em: 10 set. 2014 . 
imposto basicamente aos "de baixo" e da suspensão até mesmo de direitos trabalhistas recém-outorgados e celebrados pela propaganda governamental. As transformações vividas pelo país no período produziram fortes abalos sociopolíticos. Como efeito colateral gerado pela mobilização patriótica em prol da guerra contra o Eixo, a classe trabalhadora assumiu um destacado protagonismo político no país a partir de 1945, lutando tanto pela garantia de direitos sociais quanto pela conquista de novas reivindicações. ${ }^{58}$

Afinal de contas, tratava-se de uma ditadura entrando numa guerra em defesa da democracia, de uma sociedade profundamente racista se mobilizando contra doutrinas de supremacia branca. Um governo que abraçava justamente naquele momento o nacionalismo de massas, ao mesmo tempo estabelecia uma aliança militar com os Estados Unidos que, se de um lado contribuiria para criar condições de aprofundamento do processo de industrialização do país, a curto prazo implicava em concessões que afetavam gravemente a soberania nacional. Os trabalhadores brasileiros foram atores decisivos em todas essas dimensões daquele período de acontecimentos intensos e acelerados.

O artigo de Edinaldo Antonio Oliveira Souza, que abre o dossiê intitulado "Trabalhadores, sindicatos e lutas por direitos na Bahia no final da Segunda Guerra Mundial", trata da recepção dos discursos do esforço de guerra pelas lideranças sindicais e por diversos setores do operariado baiano, a partir de uma interessante interlocução entre os processos instaurados na Justiça do Trabalho e os debates registrados em diversos jornais que circulavam no estado.

Fernanda Lima Rabelo, em "Na era da expertise: formação e qualificação dos servidores públicos na Segunda Guerra", discute projetos e discursos veiculados pelo Departamento Administrativo do Serviço Público (DASP) no período do Estado Novo, analisando seus posicionamentos e possíveis inflexões diante do conflito mundial no processo formativo desses "trabalhadores do estado".

Já Tassiane Mélo de Freitas, com o artigo “Viva a classe operária mineira unida! Contra a guerra imperialista!': os mineiros de carvão do Rio Grande do Sul

58 Uma agenda de pesquisa relevante que pode ser desenvolvida a partir deste balanço sobre a conjuntura da Segunda Guerra Mundial diz respeito à comparação com as conclusões de trabalhos relevantes sobre outros momentos da história brasileira. Ricardo Salles, por exemplo, analisa as consequências da Guerra do Paraguai (1864-1870) para as camadas populares no período imperial, particularmente as famílias escravas. Dentre elas, o autor aponta o impulsionamento do discurso próabolição e da atuação dos escravizados na luta por direitos. SALLES, Ricardo. Guerra do Paraguai: escravidão e cidadania na formação do Exército. Rio de Janeiro: Paz e Terra, 1990. 
e o esforço de guerra (1942-1945)", aborda o desenvolvimento da indústria do carvão mineral gaúcha no contexto do esforço de guerra, que combinava altos lucros com precárias condições de trabalho, destacando os posicionamentos dos operários mineiros da região do Baixo Jacuí/RS diante dessas tensões, a partir de fontes inéditas.

Patrícia Costa de Alcântara busca compreender os objetivos do Estado Novo e o alcance das suas campanhas de mobilização junto aos trabalhadores durante a guerra em "Limites e alcances da propaganda do Estado Novo para mobilização nacional durante a Segunda Guerra Mundial". A autora oferece uma instigante análise de processos trabalhistas instaurados nas Juntas de Conciliação e Julgamento de Belo Horizonte/MG, assim como de matérias publicadas pela Revista do Trabalho e pelo jornal Estado de Minas.

Utilizando como fontes principais um processo da Justiça do Trabalho e reportagens do jornal Correio do Povo, Tamires Xavier Soares analisa as posturas governamentais e da classe trabalhadora diante da escassez de alimentos no período da guerra e a majoração de seus preços, no artigo intitulado "A guerra no prato: o problema de abastecimento de carne verde no Rio Grande do Sul durante a Segunda Guerra Mundial".

Encerrando o dossiê, o artigo "Os Febianos: experiência, consciência e agência dos trabalhadores brasileiros convocados para a guerra na Força Expedicionária Brasileira-FEB (1943-1945)", de Frederico Soares Ribeiro, apresenta uma discussão bastante original sobre os trabalhadores civis que foram convocados para lutar no front e eram comandados por militares de carreira do Exército. Ribeiro analisa as identidades desses trabalhadores e suas mobilizações, a partir dos testemunhos de expedicionários, reportagens de um jornal produzido pelos próprios pracinhas e realizadas anotações em seus Certificados de Reservista.

Além de ampliar a circulação dos resultados obtidos por esses historiadores, o presente dossiê pretende estimular o surgimento de novos projetos com foco nos impactos da Segunda Guerra Mundial nos mundos do trabalho. Esses estudos recentes demonstram que o Brasil tem uma contribuição importante a oferecer para o avanço do debate historiográfico internacional sobre o tema. Entendemos também que as pesquisas que reveem esse período crucial da história do trabalho no Brasil trazendo o conflito global para o primeiro plano ajudam a estabelecer bases para mudanças mais profundas nos nossos paradigmas historiográficos, até hoje bastante segmentados no que diz respeito à relação entre história doméstica e relações internacionais. 